\title{
How Does Age Matter in the Linkage between Religious Involvement and Adult Self-Rated Health?
}

\author{
Li Zhang \\ China University of Political Science and Law, Beijing, China \\ Email: Lzhang@cupl.edu.cn
}

Received 21 March 2015; accepted 17 April 2015; published 22 April 2015

Copyright (C) 2015 by author and Scientific Research Publishing Inc.

This work is licensed under the Creative Commons Attribution International License (CC BY). http://creativecommons.org/licenses/by/4.0/

cc) (7)

Open Access

\begin{abstract}
Through conducting an age, period, and cohort analysis by running cross-classified random effect models, this research studies how age plays a role in the religious involvement and health relationship. Data are drawn from the U.S. General Social Survey, 1972 to 2008. For the most part, the results show that after controlling for the cohort and period effects, there is a loss of advantages in health with age for those who are more involved in religion. This finding suggests that when the period and cohort effects are taken into consideration, the cumulative advantage theory may not be supported in this case.
\end{abstract}

\section{Keywords}

Age, Religion, Religiosity, Self-Rated Health, Cohort, Period

\section{Introduction}

In social sciences, there is a rich body of literature examining the linkage between religious involvement and adult's mental and physical health (Ellison, 1995; Ellison \& Fan, 2008; Ferraro \& Albrecht-Jensen, 1991; Koenig, Smiley, \& Gonzales, 1988; Levin \& Markides, 1985; Musick, House, \& Williams, 2004; Nicholson, Rose, \& Bobak, 2009). Most of the literature shows that various dimensions of religious involvement promote an individual's physical and mental well-being and longevity, reduce the risk of certain health problems and lower the level of depression (Ellison, 1991; Ellison \& Taylor, 1996; Idler, 1987; Levin \& Vanderpool, 1987; Musick et al., 2004; Sternthal, Williams, Musick, \& Buck, 2010). When the age effect is taken into consideration, previous studies seem to suggest that the positive effect of religious involvement on adult health remains strong and may become even stronger in older ages. For instance, prior studies show that the frequency of devotional activity 
varies by age. The frequency of devotional activity increases with age and becomes especially high among elderly adults (Ainlay \& Smith, 1984; Guy, 1982). Elderly adults are also found to be more inclined to turn to intrapsychic coping strategies, such as religion, to manage stressors and problems that are perceived to be insoluble (Corsentino, Collins, Sachs-Ericsson, \& Blazer, 2009; Reyes-Ortiz et al., 2008). Witter and colleagues (1985) find that the high correlation between religion and subjective well-being becomes more significant for samples of older than younger adults (Witter, Stock, Okun, \& Haring, 1985). Thus, researchers claim that the effects of divine interaction on well-being increase with age (Ellison, 1991). This is perhaps due to the greater salience of matters of "ultimate concern" in later life (Koenig et al., 1988). Given the findings regarding the age effects on religious involvement and adult health shown in prior research, one may hypothesize that the magnitude of religious influence on an individual's health increases with age. This is perhaps because the health disparities are due to the fact that early life advantages or disadvantages accumulate with age over the life course (Dannefer, 2003).

Such a hypothesis, however, is untested when put in the period and cohort context. This is because most of the above analyses on religion, age and health are mostly concerned with cross-sectional individual-level characteristics and religious involvement. We know relatively little beyond the health disparities that correlate with religious factors and age at a static point in time. Put differently, the role of three time-related variations - age, period, and cohort effects - has not been clarified simultaneously when discussing how various levels of religious involvement produce disparities in health. Scholars do document that health is affected by age over the individual life course with a cohort effect in different historical times (Chen, Yang, \& Liu, 2010; Lynch, 2003; Yang, 2007). Religious factors, in addition, are also found to be influenced by period and cohort effects in recent research (Schwadel, 2010). Given these considerations, there is a need to disentangle period and cohort effects when testing the age effect in the study of health disparities caused by religious involvement. The study uses the recently developed methodologies of cross-classified random effect models to analyze time-series data in the United States from the General Social Survey (GSS). Using this time-series dataset spanning 36 years, the research carries out a longitudinal study of changes in health that is associated with religious involvement differentials for multiple cohorts of individuals in the United States. The research aims to test the hypothesis raised earlier that whether the positive effect of religious involvement on adult health increases by age, controlling for the period and cohort effects.

\section{The Period and Cohort Effects}

Since the period and cohort effects are important controls of this research, the article introduces the two effects and discusses why they are included in the analysis. Period refers to a specific time point in history. A period may be a year or a decade. Period effects are seen as changes among people of all ages from one historical period to another (Schwadel, 2010). Period effects usually occur due to social, cultural and economic changes that begin to take place in certain time periods. These changes induce similar changes in individual health of all ages. For instance, the 1964 U.S. Surgeon General's report identified tobacco consumption as the principal cause of lung cancers, which led to legislation to ban smoking in public areas (Rogers, Hummer, Krueger, \& Pampel, 2005). As a result, over time, the U.S. adults aged 20 years and older who smoked dropped from $44 \%$ in 1965 to $23 \%$ in 2000 . The percentage of adults who formally smoked changed from $14 \%$ to $23 \%$; and the percent of never smokers increased from $44 \%$ to $54 \%$ (CDC, 2002). This example shows period effects.

Birth cohort refers to a group of people who were born at the same time. Cohort effects are associated with changes across groups of individuals who experience an initial event such as birth in the same year or years. Cohort effects indicate changes across the birth cohorts regardless of age. These effects represent the effects of formative experience for successive age groups in successive time periods (Glenn, 2003; Ryder, 1965). As Ryder (1965) argues in a classic essay, social change occurs because of individual change or an ongoing massive process of personnel replacement in which older cohorts are succeeded by younger ones with different attitudes and behaviors. This type of population turnover has been called "cohort replacement" or "cohort succession" in subsequent work (Firebaugh, 1989). The distinction between period effects and cohort effects lies in the way in which people view the causes of social changes. Health outcomes, in particular, can improve or become worse over time due to some relevant historical events experienced by various birth cohorts. This reflects period effects. On the other hand, health outcomes may get better or worse across successive birth cohorts, which shows cohort 
effects.

The discussion of the period and cohort effects has been shown in religious involvement. Chaves (1991), for instance, has argued that cohort effects exist when studying religious involvement because recent cohorts attend church at lower rates than did preceding ones; period effects also play a role because the social process "keeps individuals away from formal religious practices" (Chaves, 1991: p. 502). Firebaugh \& Harley's (1991) research echoes Chaves' arguments by showing that recent cohorts are less inclined to attend church than were earlier cohorts at the same age. They contend that cohort replacement reduces church attendance as older and higher-attendance cohorts are succeeded by younger and lower-attendance ones. Chaves (1989) has characterized the Protestant church attendance as negative across-cohort change but positive within-cohort change, meaning there is a declining attendance across successive birth-cohorts and cross-the-broad "resurgence" in attendance, i.e., the positive effects (Chaves, 1991: p. 488). A recent study conducted by Schwadel (2010a) shows large changes across cohorts and periods in religious attendance. Schwadel's (2010b) research also displays period and cohort effects by examining the individual reports of no religious affiliation and religious disaffiliation in the United States. Cohort effects in the research were showed by a tremendous increase in percentages of Americans with no religious preference in recent birth cohorts; and period effects were revealed by a period-based increase in nonaffiliation during 1990 to 2006 in the U.S. These findings suggest the compound age, period and cohort effects associated with religious changes and suggest that it is necessary to simultaneously control the period and cohort effects to evaluate how age plays a role in the connection between religious involvement and health. In the following section of the paper, the paper details the data and measures, along with the methods, used to carry out a longitudinal study on religious involvement and health.

\section{Data and Measures}

Data from the General Social Surveys (GSS) conducted over the 36-year period from 1972 to 2008 are used to perform the analysis. The GSS, an ongoing survey conducted annually or biennially by the National Opinion Research Center since 1972, is a nationally representative survey of English-speaking adults aged 18 or older in the United States. The survey monitors the attitudes and behaviors of adults in the United States with core items being repeated as well as new items being added every year (Davis, Smith, \& Marsden, 2004). Multistage stratified probability sampling strategy is used to choose non-institutionalized adults ages 18 or older in the United States, which yields sample sizes ranging from about 1500 to 3000 across survey years.

In survey years, the GSS contains an item on self-reported health, which asks: "Would you say your own health, in general, is excellent, good, fair, or poor?" The responses in this analysis are coded as "1" if the respondent reported his/her health as "poor", as " 2 " if reported as "fair", as " 3 " if claimed as "good" and as " 4 " if stated as "excellent". Despite the simplicity of the health measure in the GSS, evidence from the existing literature proves the efficiency of the measure when capturing an individual's health condition (Ellison \& Fan, 2008; Link, Phelan, Miech, \& Westin, 2008; Martin, Pescosolido, Olafsdottir, \& Mcleod, 2007; Olafsdottir, 2007; Olafsdottir \& Pescosolido, 2009; Scheitle \& Adamczyk, 2010; Warren \& Hernandez, 2007). Thus, this question is used as a measuring tool of an individual's overall health.

Four religious measures are used to represent religious involvement, which are denominational ties, social integration, divine interaction, and existential certainty. They represent four distinct aspects of religious involvement (Ellison, 1991). The denominational preference measure includes four categories: 1) Protestant, 2) Catholic, 3) other religions, and 4) no religion. Based on the four categories, four dummy variables are created with Protestants being the reference group. The second independent variable, the role of religion as a source of social integration, is measured by frequency of attendance at religious services which is coded as three dummy variables $(1=$ less than once a month, $0=$ otherwise; $1=$ one to three times a month, $0=$ otherwise; $1=$ every week or more, $0=$ otherwise; reference $=$ less than once a month). The divine interaction variable, the third key independent variable, is coded as three dummy variables which measure how often the respondent prays $(1=$ once a week or less, $0=$ otherwise; $1=$ several times a week, $0=$ otherwise; $1=$ several times a day, $0=$ otherwise; reference $=$ several times a week). The fourth key variable, existential certainty, is measured by the extent to which a person feels certain the God exists. I code the existential certainty variable as three dummy variables $(1=$ do not believe in God, $0=$ otherwise; $1=$ believe with doubts, $0=$ otherwise; $1=$ believe without doubts, 0 $=$ otherwise; reference $=$ believe without doubts).

In addition to the key religious involvement variables, a variety of control variables that could be related to an 
individual's health are also included. The demographic control variables include sex (female $=0$, male $=1$ ), race (white, black or other race; reference $=$ non-white) and marital status (married $=1$, otherwise $=0$; reference $=$ non-married). The measure of race is included because blacks tend to have poorer health outcomes than whites, and are more likely to lack health insurance and to live in places of concentrated poverty where opportunities for healthy eating and exercising are limited (Read \& Emerson, 2005). Marital status is controlled in the study considering the fact that marriage has a protective effect on individual health and mortality (Lillard \& Waite, 1995). The analysis also adjusts for the respondent's socioeconomic characteristics because people with higher socioeconomic status (SES) are found to be more likely to report better health and lower rates of disability, morbidity and mortality (Rogers, Rogers, \& Belanger, 1992; Zimmer, Chayovan, Lin, \& Natividad, 2004). The socioeconomic controls are education (years of education completed), income and employment status. Income is measured on a five-point scale of total family income where $1=$ less than $\$ 10,000,2=\$ 10,000$ to $\$ 14,999,3=$ $\$ 15,000$ to $\$ 19,999,4=\$ 20,000$ to $\$ 24,999$ and $5=\$ 25,000$ and over. The income measure in the GSS has been converted to 1986 dollars considering inflation. Missing values are omitted in the analysis. Employment status is coded as a dummy variable, which is coded as " 1 " if the respondent was working full time and " 0 " if the respondent was working part-time, or temporarily not working, unemployed, retired, at school, or claimed some other working status. Those who did not report working full time are the reference group.

The level-2 unit of analysis is cohort-by-period cells. Survey years and birth cohorts are level-2 contextual variables in hierarchical models, which will be discussed in the methods section below. Each survey year is a separate period. The definitions and descriptive statistics of all variables included in the analysis are presented in Table 1.

Table 1. Summary statistics for all variables in the analysis: GSS, 1972-2008.

\begin{tabular}{|c|c|c|c|c|c|}
\hline Variable & Description and Coding & Mean (or \%) & S.D. & Min & Max \\
\hline \multicolumn{6}{|l|}{ Dependent variable } \\
\hline R's SRH & $1=$ poor to $4=$ excellent & & & 1 & 4 \\
\hline Poor & & 5.6 & & & \\
\hline Fair & & 18.7 & & & \\
\hline Good & & 44.9 & & & \\
\hline Excellent & & 30.9 & & & \\
\hline \multicolumn{6}{|l|}{ Independent variables } \\
\hline \multicolumn{6}{|l|}{$\begin{array}{l}\text { Level } 1 \text { Variables Key religious } \\
\text { involvement variables }\end{array}$} \\
\hline 1) Denominational preference & R's religious preference (ref. $=$ Protestant $)$ & & & 0 & 1 \\
\hline Protestant & $1=$ Protestant, $0=$ otherwise & 59.8 & & & \\
\hline Catholic & $1=$ Catholic, $0=$ otherwise & 24.6 & & & \\
\hline Other & $1=$ Other, $0=$ otherwise & 5.4 & & & \\
\hline None & $1=$ None, $0=$ otherwise & 10.2 & & & \\
\hline \multicolumn{6}{|l|}{ 2) Social integration } \\
\hline Attends religious services & $\begin{array}{l}\text { Frequency } R \text { attends religious services } \\
\text { (ref. = Attends } 1 \text {, less than once a month) }\end{array}$ & & & 0 & 1 \\
\hline Attends 1 & $1=$ Less than once a month, $0=$ otherwise & 50.0 & & & \\
\hline Attends 2 & $1=1-3$ time a month, $0=$ otherwise & 16.1 & & & \\
\hline Attends 3 & $1=$ Every week or more, $0=$ otherwise & 33.7 & & & \\
\hline \multicolumn{6}{|l|}{ 3) Divine relations } \\
\hline How often $R$ prays & Frequency R prays (ref. $=$ Pray 2 , several times a week) & & & 0 & 1 \\
\hline Prays 1 & $1=$ once a week or less, $0=$ otherwise & 30.0 & & & \\
\hline Prays 2 & $1=$ several times a week, $0=$ otherwise & 43.2 & & & \\
\hline Prays 3 & $1=$ several times a day, $0=$ otherwise & 26.8 & & & \\
\hline
\end{tabular}




\section{Continued}

4) Existential certainty

Certainty 1

Certainty 2

Certainty 3

$\underline{\text { Other variables }}$

Age (mean)

Sex

Male

Female

Race and ethnicity

White

Black or other

Other

Marital status

Married

Never married

Widowed

Separated

Never married

Highest year of school completed

Total family income

Less than $\$ 10,000$

$\$ 10,000$ - \$14,999

$\$ 15,000$ - 19,999

$\$ 20,000$ - \$24,999

$\$ 25,000$ and over

Labor force status

Working fulltime

Working part time

Temp. not working

Unemployed

Retired

At school

Other

Level-2 variables

Period

Cohort
$\mathrm{R}$ feels certain about/believes God's existence

(ref. = believe without doubts)

$1=$ Don't believe in God, $0=$ otherwise

$1=$ Believe with doubts, $0=$ otherwise

$1=$ Believe without doubts, $0=$ otherwise

Age of R.

Sex of the respondent

$(1=$ male, $0=$ female; ref. $=$ female $)$$$
45
$$

$\begin{array}{ccc}17.4 & 18 & 89 \\ & 0 & 1\end{array}$

45.9

54.1

$\mathrm{R}$ 's race $(1=$ white, $0=$ Black or other; ref. $=0$, Black or other $)$

\section{7}

13.8

4.5

R's marital status $(1=$ married, $0=$ otherwise; ref. $=0$, otherwise $)$

R's year of schooling

$\begin{array}{llll}12.7 & 3.1 & 0 & 20\end{array}$

Family income in 1986 dollars; ranges from $1=$ less than $\$ 10,000$ to $5=\$ 25,000$ or more

R's work status

$(1=$ working full time, $0=$ otherwise; ref. $=0$, otherwise $)$

Note: some sub-categories may not add up to $100 \%$ due to rounding. "R" refers to the respondent. Source: The U.S. General Social Survey conducted by the National Opinion Research Center. 


\section{Methods}

Given that the study puts age, period and cohort effects simultaneously in the model to examine the age effect in the religious involvement and health relationship, the age-period-cohort (APC) approach is an appropriate method to be used in the analysis. The conventional statistical APC analysis developed by Mason and associates (1973) faces a major challenge of the underidentification problem induced by the exact linear dependency between age, period and cohort (Period $=$ Age + Cohort) when the time intervals used to tabulate the data are of the same length for the age and period components. Considering the underidentification problem associated with conventional APC approach and the multilevel structure of the GSS data design, this research uses cross-classified random effect models (CCREMs) to conduct analyses. Individuals are the level-1 unit of analysis. Periods and cohorts operate as rows and columns in a matrix generating cohort-by-period cells, which become the level2 unit of analysis. The CCREMs adjust for the dependency between age, period and cohort by considering period and cohort as cross-classified level-2 units. Beyond providing random cohort and period effects, CCREMs allow for random effects of independent variables, which is used to test for cross-cohort and cross-period variations in the effects of key independent (religious involvement) variables. Cohort- and period-specific random-effects coefficients suggest potential across-cohort and across-period changes in the effects of religious involvement on health. Fienberg \& Mason (1982) have also proposed using a nonlinear transformation approach which applies a nonlinear transformation such as a polynomial to ensure the relationship of at least one of the age, period and cohort covariates to others is nonlinear. Following this strategy and noting that a finding of nonlinear age effect on health and well-being (Chen et al., 2010; Yang, 2008), this study specifies models of self-rated health (SRH) as a quadratic function of age. In the GSS data, an individual respondent is nested in and cross-classified by two higher level contexts-period and cohort.

Several models are presented in the analysis. The first model only includes age and age-squared as fixed effects. This model measures the overall effects of age, period and cohort on health. Models 2 through 5 include each of the four religious involvement measures separately, controlling for the demographic and socioeconomic factors. The four religious involvement measures are not included in the same model due to multicollinearity. The full individual level or level-1 equation can be expressed as:

$$
\mathrm{Y}_{\mathrm{ijk}}=\beta_{0 \mathrm{jk}}+\beta_{1 \mathrm{jk}} \mathrm{A}+\beta_{2 \mathrm{jk}} \mathrm{A}^{2}+\beta_{3 \mathrm{jk}} \mathrm{P}+\beta_{4 \mathrm{jk}} \mathrm{I}+\beta_{5 \mathrm{jk}} \mathrm{R}+\beta_{6 \mathrm{jk}} \mathrm{C}+\sum_{p=10}^{p} \beta_{\mathrm{p}} \mathrm{Xp}+\mathrm{e}_{\mathrm{ijk}}
$$

where $Y_{i j k}$ represents the ordinal response outcome of SRH condition of the ith respondent for $i=1, \cdots$, njk individuals within the $\mathrm{jth}$ period for $\mathrm{j}=1, \cdots, \mathrm{K}$ birth cohort. $\beta_{0 \mathrm{jk}}$ is the intercept or cell mean for respondents in period $\mathrm{j}$ and cohort $\mathrm{k}$; "A" and " $\mathrm{A}$ " symbolize age and age-squared (see previous paragraphs for the rationale that includes the quadratic term of age), respectively. "P" indicates "denominational preference"; "I" represents "social integration"; " $R$ " denotes "divine relations", and "C" indicates "existential certainty". $\beta_{1}$ through $\beta_{5}$ are the individual level fixed effects for age $(\mathrm{A})$, age-squared $\left(\mathrm{A}^{2}\right)$, denominational preference $(\mathrm{P})$, social integration $(\mathrm{I})$, divine relations $(\mathrm{R})$ and existential certainty $(\mathrm{C}) . \mathrm{X}_{\mathrm{p}}$ designates the vector of other individual-level covariates that interact with age and control variables. $\beta_{\mathrm{p}}$ represents other individual-level fixed effects where $\mathrm{P}$ is the maximum number of covariates. $\mathrm{e}_{\mathrm{ijk}}$ represents an individual level random error term.

The level-2 model can be expressed as:

$$
\alpha_{\mathrm{jk}}=\gamma_{0}+\mathrm{p}_{0 \mathrm{j}}+\mathrm{c}_{0 \mathrm{k}}
$$

This model specifies the overall mean varies from period to period and from cohort to cohort. $\gamma_{0}$ is the model intercept, which is the expected mean at the zero value of all level-1 variables averaged over all periods and cohorts. Here $\mathrm{p}_{0 \mathrm{j}}$ and $\mathrm{c}_{0 \mathrm{k}}$ are the residual random effects of period and cohort, respectively. The cell mean, $\beta_{0 \mathrm{jk}}$, is equal to the sum of the overall mean or intercept $\left(\gamma_{0}\right)$, the residual random effect of period $\mathrm{j}\left(\mathrm{p}_{0 \mathrm{j}}\right)$ and the residual random effect of cohort $\mathrm{k}\left(\mathrm{c}_{0 \mathrm{k}}\right)$. The residual random effects allow me to examine the effects of each cohort and period on health.

$$
\begin{aligned}
& \beta_{3 \mathrm{jk}}=\gamma_{3}+\mathrm{p}_{3 \mathrm{j}}+\mathrm{c}_{3 \mathrm{k}} \\
& \beta_{4 \mathrm{jk}}=\gamma_{4}+\mathrm{p}_{4 \mathrm{j}}+\mathrm{c}_{4 \mathrm{k}} \\
& \beta_{5 \mathrm{jk}}=\gamma_{5}+\mathrm{p}_{5 \mathrm{j}}+\mathrm{c}_{5 \mathrm{k}}
\end{aligned}
$$




$$
\beta_{6 \mathrm{jk}}=\gamma_{6}+\mathrm{p}_{6 \mathrm{j}}+\mathrm{c}_{6 \mathrm{k}}
$$

Models (3) through (6) test for random effects of denominational preference, social integration, divine relations and existential certainty on health across cohorts and periods. In these models, $\gamma_{3}, \gamma_{4}, \gamma_{5}$, and $\gamma_{6}$ represent the fixed-effects coefficients for the religious involvement variables; the symbols of $\mathrm{p}_{3 \mathrm{j}}, \cdots, \mathrm{p}_{6 \mathrm{j}}$ represent the period-specific effects of the religious involvement variables and $c_{3 \mathrm{k}}, \cdots, \mathrm{c}_{6 \mathrm{k}}$ specify the cohort-specific effects of the religious involvement factors. These models are used to test whether health outcomes that are related to religious involvement-measured by denominational preference, social integration, divine relations and existential certainty-vary by time and birth cohort. All continuous variables are sorted and centered around their overall mean.

\section{Results}

Table 2 presents findings of the estimated SRH health on religious involvement variables and other control variables from CCREMs. Among the five models that are established in the analysis, the first model only includes period, cohort covariates along with age and age-squared term. This model indicates the overall impact of age, period and cohort on health. Models 2 through 5 add four religious involvement indicators separately. As it is mentioned earlier, a full regression model which includes all religious involvement variables simultaneously is omitted due to collinearity. The fixed-effects coefficients presented in the models can be interpreted in a manner similar to ordinary least square coefficients. Some key results are also illustrated by the predicted levels of SRH in graphs.

Table 2. Regression results of SRH on religious involvement variables and other control variables from hierarchical age-period-cohort models: U.S. 1972-2008.

\begin{tabular}{|c|c|c|c|c|c|}
\hline Fixed Effects & Model 1 Coef. & Model 2 Coef. & Model 3 Coef. & Model 4 Coef. & Model 5 Coef. \\
\hline Intercept & $2.973 * * *$ & $2.356 * * *$ & $2.305 * * *$ & $2.456 * * *$ & $2.374 * * *$ \\
\hline \multicolumn{6}{|l|}{ Denominational preference variables } \\
\hline \multicolumn{6}{|l|}{ (ref. $=$ Protestant) } \\
\hline Catholic & & -0.034 & & & \\
\hline Other religion & & 0.003 & & & \\
\hline No religion & & $-0.143 * *$ & & & \\
\hline \multicolumn{6}{|l|}{ Social integration variable } \\
\hline \multicolumn{6}{|l|}{$\begin{array}{l}\text { Frequency attends religious services } \\
\text { (ref. }=\text { attend } 1,<\text { once a month) }\end{array}$} \\
\hline Attend 2 ( 1 - 3 times a month) & & & 0.011 & & \\
\hline Attend 3 (every week or more) & & & $0.052 *$ & & \\
\hline \multicolumn{6}{|l|}{ Divine interaction variable } \\
\hline \multicolumn{6}{|l|}{$\begin{array}{l}\text { Frequency prays } \\
\text { (ref. = Pray 2, a few times a week) }\end{array}$} \\
\hline Pray 1 (<=once a week) & & & & 0.073 & \\
\hline Pray 3 (several times a day) & & & & $-0.086^{*}$ & \\
\hline \multicolumn{6}{|l|}{ Existential certainty variable } \\
\hline \multicolumn{6}{|l|}{$\begin{array}{l}\text { Certainty of the existence of God } \\
\text { (ref. = certainty 3, believe God exists) }\end{array}$} \\
\hline Certainty 1 (don't believe/not sure) & & & & & $-0.145^{*}$ \\
\hline
\end{tabular}




\section{Continued}

Certainty 2 (believe with doubts)

Control variables

Age

Age $^{2}$

Sex

White

Married

Years of education

Income

Work full time

Age interaction terms

Age * Catholic

Age * other religion

Age * no religion

Age * attend services 2

Age * attend services 3

Age * pray 1

Age * pray 3

Age * certainty 1

Age * certainty 2

\begin{tabular}{|c|c|c|c|c|c|}
\hline Random Effects $^{\mathrm{a}}$ & $\begin{array}{c}\text { Variance } \\
\text { Component }\end{array}$ & $\begin{array}{c}\text { Variance } \\
\text { Component }\end{array}$ & $\begin{array}{c}\text { Variance } \\
\text { Component }\end{array}$ & $\begin{array}{c}\text { Variance } \\
\text { Component }\end{array}$ & $\begin{array}{c}\text { Variance } \\
\text { Component }\end{array}$ \\
\hline \multicolumn{6}{|l|}{ Period effect } \\
\hline Intercept & $0.0005 * * *$ & $0.0024 * * *$ & $0.0019 * * *$ & $0.0022 * * *$ & $0.0016^{* *}$ \\
\hline Catholic & & $0.0001 *$ & & & \\
\hline Other religion & & $0.0004 * *$ & & & \\
\hline No religion & & $0.0001^{*}$ & & & \\
\hline Attends services 2 & & & $0.0001 * * *$ & & \\
\hline \multicolumn{6}{|l|}{ Cohort effect } \\
\hline Intercept & $0.0063 * * *$ & $0.0008 * * *$ & $0.0014 * * *$ & 0.0001 & 0.0004 \\
\hline Catholic & & $0.0010^{*}$ & & & \\
\hline Goodness-of-fit (deviance) & 96440.91 & 79130.85 & 78517.83 & 32348.75 & 19360.35 \\
\hline
\end{tabular}

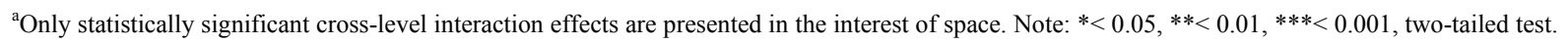
Source: The U.S. General Social Survey conducted by the National Opinion Research Center.
0.001

$0.002 * *$
$0.003^{*}$

$-0.000$

$0.002 *$

$-0.001$
0.001

$-0.001$

$0.003^{* *}$ 
Model 1 shows that with only age, period and cohort effects included in the model, the predicted average overall level of SRH is 2.97. Age has a significantly negative effect on SRH (coef. $=-0.011, p<.05$ ), which suggests that after period and cohort effects are taken into consideration, the level of SRH decreases by $1.1 \%$ with every one year increase in age. Such a negative effect is demonstrated by Figure 1.

Models 2 through 5 focus on investigating the respective effects of religious denomination, social integration, divine interaction and existential certainty on an individual's health. Additional control variables are added in the models as well. With religious involvement and control variables in the models, the effect of age-squared becomes significant. It means that age has a negative effect on health and the age effect increases slightly, as indicated by the positive effect of age-squared.

As to health outcomes associated with the religious involvement variables, significant health disparities related to religious denominational differences are shown in Model 2, net the age effect and the random period and cohort effects. As the results show, people with no religious preference have predicted SRH score $14.3 \%$ lower than Protestants, the reference group. The finding echoes the results of prior research that religious denomination influences an individual's health. Model 3 demonstrates a positive association between one's health outcomes and his/her level of social integration, measured by the frequency of religious attendance, controlling for the age, period and cohort effects. As Model 4 shows, individuals who pray more frequently (several times a day), a measure of divine interaction, are more likely to report a better health than those who pray less frequently (a few times a week). Model 5 suggests that being more certain of the God's existence improves the respondent's self-reported health. In sum, the results are largely consistent with prior findings about the religious influence on health. The significant individual-level effects of religious involvement factors on health remain even after level-2 period and cohort effects are considered. And the age effect still remains after controlling for the period and cohort effects.

The control variables - sex, marital status, race and ethnicity, education, income and labor force participation-all show significant influences on people's health. Women, whites, married people, those who worked full-time and reported higher incomes and obtained higher educational attainments tend to be healthier relative to men, non-whites, non-married population and those without full-time jobs and reported lower incomes and fewer years of schooling.

This section of the paper focuses on discussing how the health disparities related to religious involvement vary by age through examining the age interaction terms with the religious involvement variables. Figure 2 displays the trajectories of age changes in predicted level of SRH for religious groups. As it is shown in the figure, substantial health differences by age mainly occur between religious and nonreligious groups; there is hardly any health variation by age between Protestants and people with other religious affiliations. Religious people tend to rate their health better than nonreligious people in younger ages. This advantage, however, declines with age and eventually disappears when people reach their late $80 \mathrm{~s}$.

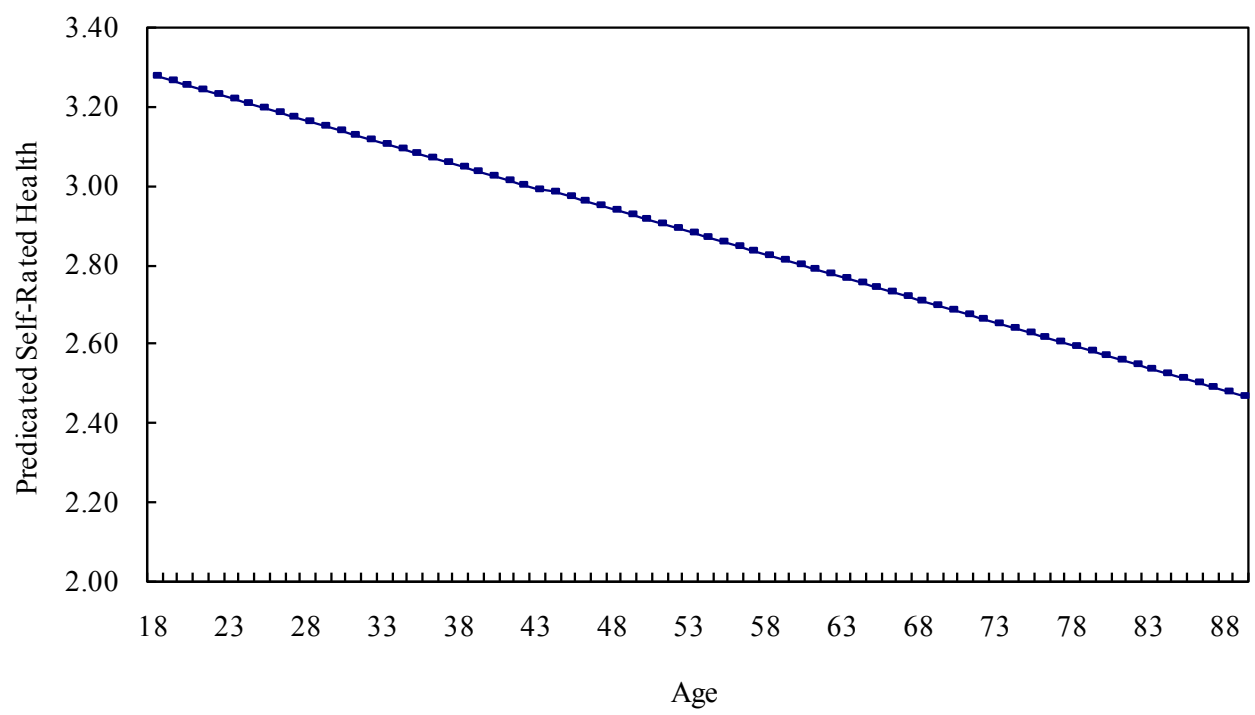

Figure 1. Overall age effects. 
In terms of social integration and health, the positive effect of attending religious services on health increases with people getting older. Those who participated in religious activities every week or more often have a predicted SRH level being 5.8\% $\left(\mathrm{e}^{0.052+0.002}\right)$ higher as compared to those who attended religious services less than once a month (the reference group), controlling for period and cohort effects. Since the age interaction term constructed by multiplying age and attending religious activities $1-3$ times a month is nonsignificant, Figure 3 only charts the reference group (those attended religious activities less than once a month) and the group that attended religious services most frequently. Figure 2 shows the "social integration advantage" is not evident before age 40. Afterwards, it gradually rises with age. The results answer the question that whether better SRH is caused by people attending religious services more frequently with age or by the cumulative advantage from a higher level of social integration since younger ages. Because the study controls age, the findings support the second scenario: adjusting for other factors, aging-related changes in the life course do impact individual health.

As suggested by Model 4, age also interacts with the divine interaction variable in affecting health. Figure 4 portrays how frequency one prays interacts with age to impact health. The age variations in health caused by a stronger divine relationship, operationalized as frequency one prays, mainly exist between the reference group (those who pray a few times a week) and the group that prayed least frequently (once a week or less). In general,

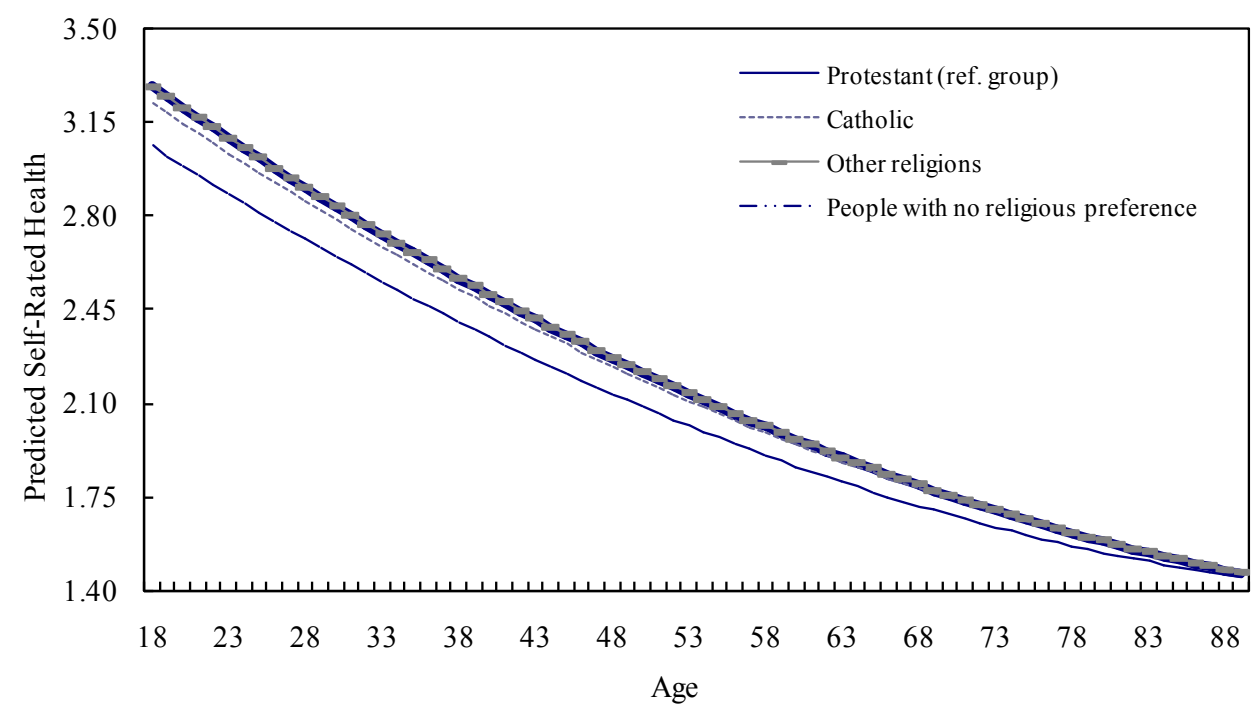

Figure 2. Age * religious denominational preference effects (Model 2).

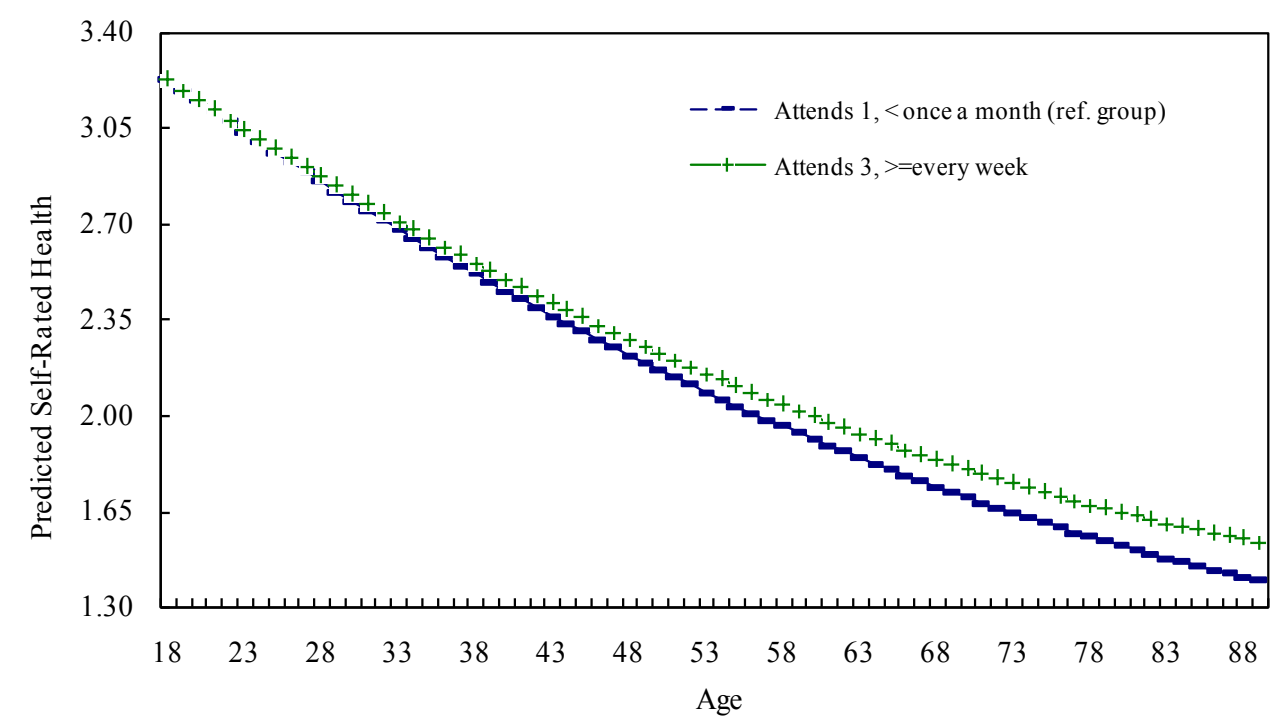

Figure 3. Age * religious attendance effects (Model 3). 
people who prayed more often show a higher predicted self-reported health. The health gaps attributable to the level of divine interaction between those who prayed moderately (a few times a week) and those who prayed least frequently (once a week or less) shrink by age. Interestingly, however, the health gaps caused by the level of divine interaction between those who prayed most frequently (several times a day) and those who prayed moderately (a few times a week) remain constant with age. The health advantage caused by one's existential certainty about God decreases with age as when compared to those who do not believe God. However, the health gaps between those who reported believing God with no doubts and those who believed God with doubts stay robust with age (see Model 5 and Figure 5). These findings imply that: First, the most religious individuals show a health advantage regardless of age. Second, the convergence and shrink in health disparities with age due to the levels of divine interaction and existential certainty only occur when comparing those who moderately practiced religion and who were least religious. Moreover, the frequency of attending religious services, a form of religious involvement, stands out by showing a stronger positive effect on individual health in older ages. I will also address this finding in the conclusion and discussion section. These results suggest that when period and cohort effects are considered, the age effect in the religious involvement and health relationship remains substantial until late old age in most of the models estimated.

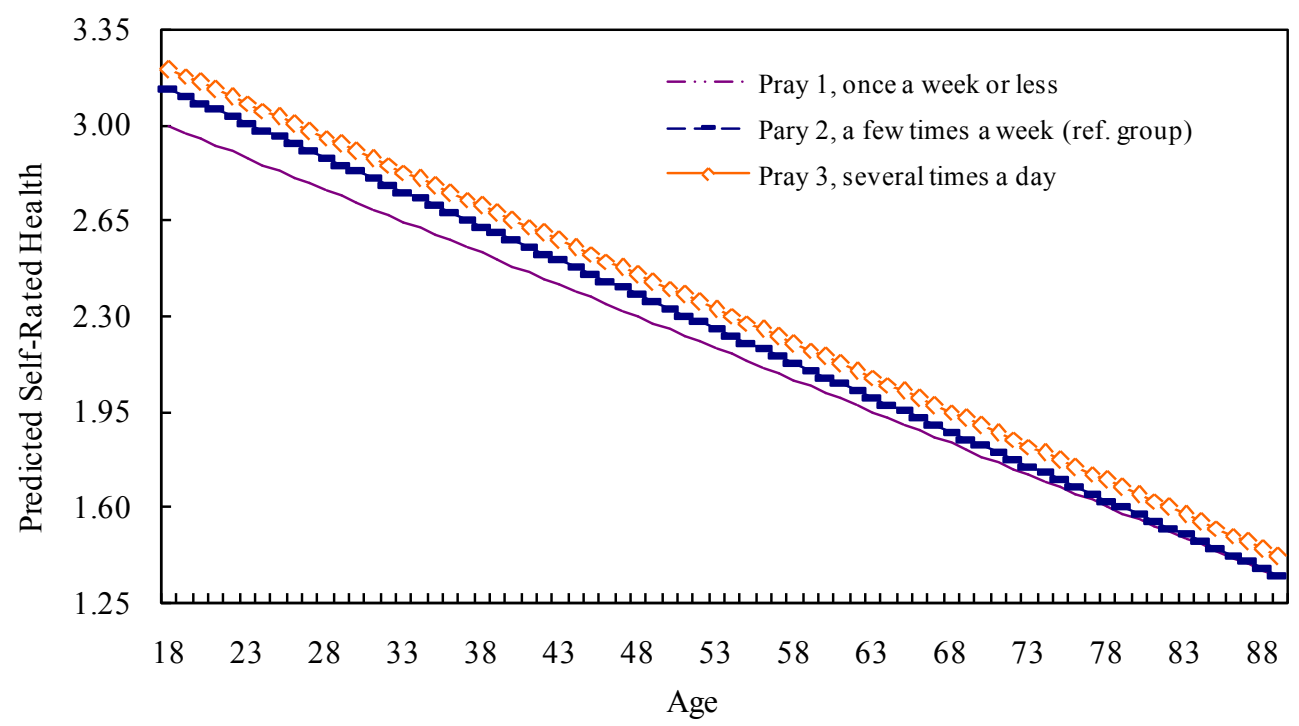

Figure 4. Age * pray effects (Model 4).

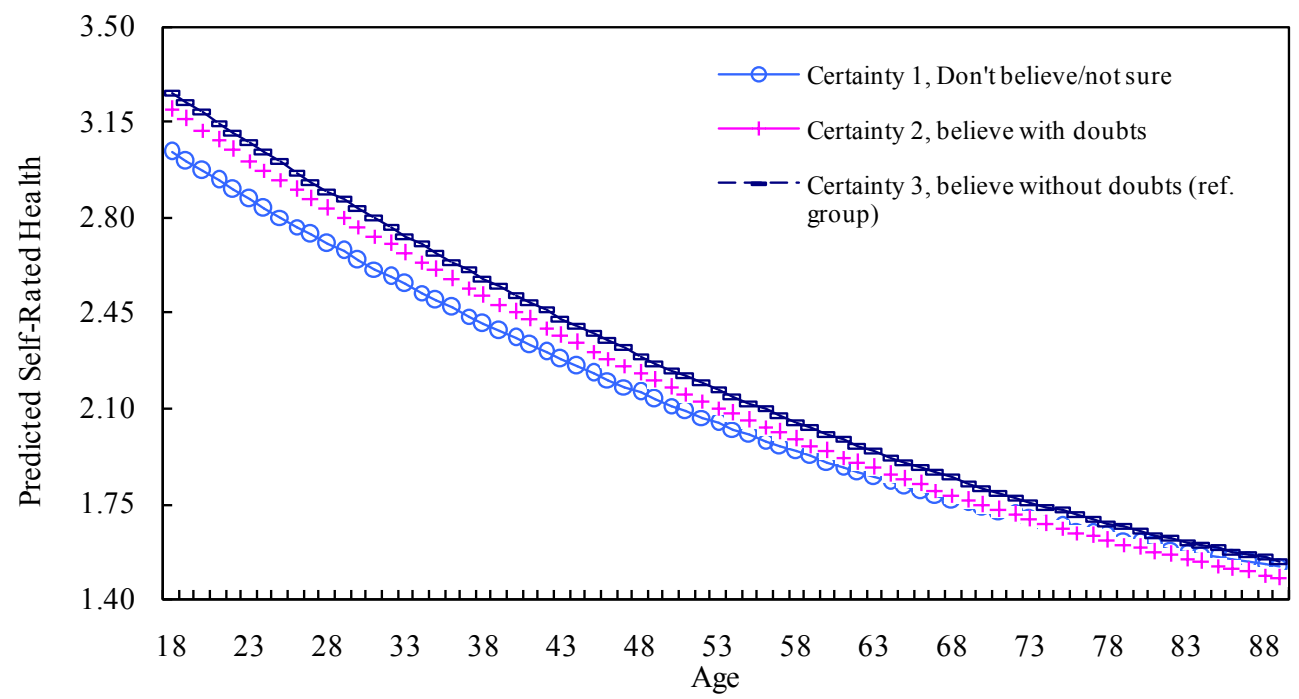

Figure 5. Age * existential certainty effects (Model 5). 


\section{Conclusion and Discussion}

Analyzing time-series data from GSS that span 36 years, this study uses cross-classified random effect models (CRREMs) to evaluate the age effect in the connection between religious involvement and adult self-rated heath, controlling for the period and birth cohort effects. Several important findings emerge here. First, the results clearly show that the negative age effects on health are strong and independent of the time period and cohort effects, confirming the age-as-leveler hypothesis. Second, the health disparities caused by three religious involvement factors - denominational preference, divine interaction, and existential certainty - decrease with age. Such a finding suggests that for the most part, the cumulative advantage/disadvantage theory that predicts health outcomes with age may not be applicable in the religious involvement and health relationship. Rather, findings of this research imply convergence in health outcomes with age. The fact that the health disparities linked to the level of religious involvement decrease with age may be explained by the following reasons: when people are getting older, they are less likely to be engaged in risky behaviors. As a result, the healthier behavior effect brought by religion diminishes. Also, the strong negative effect of age on health probably overweighs the positive effects fostered by religion that encourage healthy behaviors and eventually promote health. These factors explain why differences in SRH outcomes between nonreligious people and the mainline religious group, Protestants, decrease and finally converge in older ages. In addition, perhaps as one matures, one becomes more resilient to life stresses. The role that solace and guidance received from the belief of a powerful force given by God (Foley, 1988) and interaction with God in helping people to deal with stresses and to resolve problematic situations may not be as critical as it was in younger ages. In turn, the positive divine interaction effect on health declines as one ages. On the other hand, the fact that a stronger level of social integration, measured by frequency of service attendance, leads to better SRH outcomes remains and becomes even more evident with age increasing. This finding seems to support the cumulative advantage/disadvantage theory. It implies that the institutional support gained from joining religious communities (Cacioppo, 2002; Jones, 2004; Strawbridge, Shema, Cohen, \& Kaplan, 2001) has a cumulative effect, which somewhat distinguishes itself from other religious involvement variables. A higher level of social integration may provide religious individuals support and resources to create better SRH outcomes, particularly in older ages. This is because gaining social support from religious groups erodes the harmful impacts of factors such as loneliness and stressful life events, including widowhood and deaths of relatives and friends that occur in later ages. Individuals who are highly integrated to their church groups can deal with hardships more smoothly in later life stages. As a result, the positive influence of social integration is shown to be more substantial with age increasing. The result highlights religious involvement as a way of social integration in promoting individual health, particularly in later life, which echoes Durkheim's theory on social integration. Meanwhile, the analysis also provides evidence that the influence of religious involvement factors on health is not universal when age is taken into consideration.

All in all, this research has taken advantage of the CCREMs to reveal the age effect on health under the context of period and cohort. The findings of the research in general emphasize that religious involvement promotes adult SRH, but such an effect decreases with age. Although findings of the analysis have expanded our knowledge on religious involvement and health, several important issues merit additional analyses. First, the research finds that a higher level of social integration leads to better health outcomes and that such a positive correlation gets stronger with age. Then, can it be the case that healthier people are more likely to be engaged in religious activities so that they have shown a higher level of social integration? In other words, can it be possible that the causal relationship between religious involvement and health is the other way around? Prior literature along with the empirical findings of this research has demonstrated that the level of social integration affects health. There is a possibility that when people get older, the physical health condition affects their religious attendance. However, this research was not able to control this "selection" effect in the analysis. I have not found evidence to challenge the causal relationship shown in this research. Future work should further disentangle the causal relationship between health and religious attendance to justify the findings of this research.

Additionally, though the focus of the paper was to examine the age effect, the analyses had provided evidence that health outcomes attributed to religious involvement also varied by period and cohort. The results showed that the effect of religious involvement on health declined over time periods, but the study did not find monotonic decline in health across successive birth cohorts. The "secularization" effects may be used to explain the health results attributable to period changes. If the trend of secularization offers a reasonable explanation, then why doesn't it yield a downward trend of SRH across birth cohorts since secularization is also associated with 
cohort changes? The sociological literature has suggested that major social changes are unique in specific time periods. Certain cohorts may be immune to social changes, but they themselves have strong explanatory power of the health variations, especially at the societal level (Chen et al., 2010; Ferrao \& Kelly-Moore, 2003). These assumptions remain at the hypothesis level before they are formally tested. Future research may investigate social changes that have caused cohort and period changes to interact with age and religion when influencing adult health.

\section{Funding}

This research was supported by Program for Young Innovative Research Team in China University of Political Science and Law.

\section{References}

Ainlay, S. C., \& Smith, D. R. (1984). Aging and Religious Participation. The Journal of Gerontology, 39, 357-363. http://dx.doi.org/10.1093/geronj/39.3.357

Cacioppo, J. (2002). Loneliness and Health: Potential Mechanisms. Psychosomatic Medicine, 64, 407-417. http://dx.doi.org/10.1097/00006842-200205000-00005

CDC (2002). Number (in Millions) of Adults 18 Years and Older Who Were Current, Former, or Never Smokers, Overall and by Sex, Race, Hispanic Origin, Age, and Education, National Health Interview Surveys, Selected Years-United States, 1965-1995.

Chaves, M. (1989). Secularization and Religious Revival: Evidence from U.S. Church Attendance Rates, 1972-1986. Journal for the Scientific Study of Religion, 28, 464-477. http://dx.doi.org/10.2307/1386577

Chaves, M. (1991). Family Structure and Protestant Church Attendance: The Sociological Basis of Cohort and Age Effects. Journal for the Scientific Study of Religion, 30, 501-514. http://dx.doi.org/10.2307/1387284

Chen, F., Yang, Y., \& Liu, G. (2010). Social Change and Socioeconomic Disparities in Health over the Life Course in China: A Cohort Analysis. American Sociological Review, 75, 126-150. http://dx.doi.org/10.1177/0003122409359165

Corsentino, E. A., Collins, N., Sachs-Ericsson, N., \& Blazer, D. G. (2009). Religious Attendance Reduces Cognitive Decline Among Older Women With High Levels of Depressive Symptoms. Journal of Gerontology, 64A, 1283-1289.

Dannefer, D. (2003). Cumulative Advantage/Disadvantage and the Life Course: Cross-Fertilizing Age and Social Science Theory. The Journal of Gerontology, 58, S327-S337. http://dx.doi.org/10.1093/geronb/58.6.S327

Davis, J. A., Smith, T. W., \& Marsden, P. V. (2004). General Social Surveys: Cumulative Codebook, 1972-2004. Chicago, IL: National Opinion Research Center.

Ellison, C. G. (1991). Religious Involvement and Subjective Well-Being. Journal of Health and Social Behavior, 32, 80-99. http://dx.doi.org/10.2307/2136801

Ellison, C. G. (1995). Race, Religious Involvement and Depressive Symptomatology in a Southeastern U.S. Community. Social Science \& Medicine, 40, 1561-1572. http://dx.doi.org/10.1016/0277-9536(94)00273-V

Ellison, C. G., \& Fan, D. (2008). Daily Spiritual Experiences and Psychological Well-Being among US Adults. Social Indicators Research, 88, 247-271. http://dx.doi.org/10.1007/s11205-007-9187-2

Ellison, C. G., \& Taylor, R. J. (1996). Turning to Prayer: Social and Situational Antecedents of Religious Coping among African Americans. Review of Religious Research, 38, 111-131. http://dx.doi.org/10.2307/3512336

Ferrao, K. F., \& Kelly-Moore, J. A. (2003). Cumulative Disadvantage and Health: Long-Term Consequences of Obesity? American Sociological Review, 68, 707-729. http://dx.doi.org/10.2307/1519759

Ferraro, K. F., \& Albrecht-Jensen, C. M. (1991). Does Religion Influence Adult Health? Journal for the Scientific Study of Religion, 30, 193-202. http://dx.doi.org/10.2307/1387213

Fienberg, S. E., \& Mason, W. M. (1982). Specification and Implementation of Age, Period and Cohort Models. New York: Springer-Verlag.

Firebaugh, G. (1989). Methods for Estimating Cohort Replacement Effects. Sociological Methodology, 19, $243-262$. http://dx.doi.org/10.2307/270954

Firebaugh, G., \& Harley, B. (1991). Trends in U.S. Church Attendance: Secularization and Revival, or Merely Lifecycle Effects? Journal for the Scientific Study of Religion, 30, 487-500. http://dx.doi.org/10.2307/1387283

Foley, D. P. (1988). Eleven Interpretations of Personal Suffering. Journal of Religion and Health, 27, 321-328. http://dx.doi.org/10.1007/BF01533200

Glenn, N. D. (2003). Distinguishing Age, Period, and Cohort Effects. In J. T. Mortimer, \& M. J. Shanahan (Eds.), Handbook 
of the Life Course (Vol. VI, pp. 465-476). New York: Springer Publisher.

Guy, R. F. (1982). Religion, Physical Disabilities, and Life Satisfaction in Older Age Cohorts. International Journal of Aging and Human Development, 15, 225-232. http://dx.doi.org/10.2190/3C3M-CBVK-KTVH-BDNG

Idler, E. L. (1987). Religious Involvement and the Health of the Elderly: Some Hypotheses and an Initial Test. Social Forces, 66, 226-238. http://dx.doi.org/10.1093/sf/66.1.226

Jones, J. W. (2004). Religion, Health, and the Psychology of Religion: How the Research on Religion and Health Helps Us Understand Religion. Journal of Religion and Health, 43, 317-327. http://dx.doi.org/10.1007/s10943-004-4299-3

Koenig, H. G., Smiley, M., \& Gonzales, J. P. (1988). Religion, Health and Aging: A Review and Theoretical Investigation. Westport, CT: Greenwood Press.

Levin, J. S., \& Markides, K. S. (1985). Religious Attendance and Subjective Health. Journal for the Scientific Study of Religion, 25, 31-40. http://dx.doi.org/10.2307/1386061

Levin, J. S., \& Vanderpool, H. Y. (1987). Is Frequent Religious Attendance Really Conducive to Better Health? Toward an Epidemiology of Religion. Social Science and Medicine, 24, 589-600. http://dx.doi.org/10.1016/0277-9536(87)90063-3

Lillard, L. A., \& Waite, L. J. (1995). Til Death Do Us Part: Marital Disruption and Mortality. American Journal of Sociology, 100, 1131-1156. http://dx.doi.org/10.1086/230634

Link, B. G., Phelan, J. C., Miech, R., \& Westin, E. L. (2008). The Resources that Matter: Fundamental Social Causes of Health Disparities and the Challenge of Intelligence. Journal of Health and Social Behavior, 49, 72-91. http://dx.doi.org/10.1177/002214650804900106

Lynch, S. M. (2003). Cohort and Life-Course Patterns in the Relationship between Education and Health: A Hierarchical Approach. Demography, 40, 309-331. http://dx.doi.org/10.1353/dem.2003.0016

Martin, J. K., Pescosolido, B. A., Olafsdottir, S., \& Mcleod, J. D. (2007). The Construction of Fear: Americans' Preferences for Social Distance from Children and Adolescents with Mental Health Problems. Journal of Health and Social Behavior, 48, 50-67. http://dx.doi.org/10.1177/002214650704800104

Mason, K. O., Mason, W. M., Winsborough, H. H., \& Poole, W. K. (1973). Some Methodological Issues in Cohort Analysis of Archival Data. American Sociological Review, 38, 242-258. http://dx.doi.org/10.2307/2094398

Musick, M. A., House, J. S., \& Williams, D. R. (2004). Attendance at Religious Services and Mortality in a National Sample. Journal of Health and Social Behavior, 45, 198-213. http://dx.doi.org/10.1177/002214650404500206

Nicholson, A., Rose, R., \& Bobak, M. (2009). Association between Attendance at Religious Services and Self-Reported Health in 22 European Countries. Social Science \& Medicine, 69, 519-528. http://dx.doi.org/10.1016/j.socscimed.2009.06.024

Olafsdottir, S. (2007). Fundamental Causes of Health Disparities: Stratification, the Welfare State, and Health in the United States and Iceland. Journal of Health and Social Behavior, 48, 239-253. http://dx.doi.org/10.1177/002214650704800303

Olafsdottir, S., \& Pescosolido, B. A. (2009). Drawing the Line: The Cultural Cartography of Utilization Recommendations for Mental Health Problems. Journal of Health and Social Behavior, 50, 228-244. http://dx.doi.org/10.1177/002214650905000208

Read, J. G., \& Emerson, M. O. (2005). Racial Context, Black Immigration and the U.S. Black/White Health Disparity. Social Forces, 84, 181-199. http://dx.doi.org/10.1353/sof.2005.0120

Reyes-Ortiz, C. A., Berges, I. M., Raji, M. A., Koenig, H. G., Kuo, Y.-F., \& Markides, K. S. (2008). Church Attendance Mediates the Association between Depressive Symptoms and Cognitive Functioning among Older Mexican Americans. Journal of Gerontology, 63, 480-486. http://dx.doi.org/10.1093/gerona/63.5.480

Rogers, R. G., Rogers, A., \& Belanger, A. (1992). Disability-Free Life among the Elderly in the United States: Sociodemographic Correlates of Functional Health. Journal of Aging and Health, 4, 19-42. http://dx.doi.org/10.1177/089826439200400102

Rogers, R., Hummer, R. A., Krueger, P. M., \& Pampel, F. C. (2005). Mortality Attributable to Cigarette Smoking in the United States. Population and Development Review, 31, 259-292. http://dx.doi.org/10.1111/j.1728-4457.2005.00065.x

Ryder, N. B. (1965). The Cohort as a Concept in the Study of Social Change. American Sociological Review, 30, 843-861. http://dx.doi.org/10.2307/2090964

Scheitle, C. P., \& Adamczyk, A. (2010). High-Cost Religion, Religious Switching, and Health. Journal of Health and Social Behavior, 51, 325-342. http://dx.doi.org/10.1177/0022146510378236

Schwadel, P. (2010a). Age, Period, and Cohort Effects on U.S. Religious Service Attendance: The Declining Impact of Sex, Southern Residence, and Catholic Affiliation. Sociology of Religion, 71, 2-24. http://dx.doi.org/10.1093/socrel/srq005

Schwadel, P. (2010b). Period and Cohort Effects on Religious Nonaffiliation and Religious Disaffiliation: A Research Note. Journal for the Scientific Study of Religion, 49, 311-319. http://dx.doi.org/10.1111/j.1468-5906.2010.01511.x 
Sternthal, M. J., Williams, D. R., Musick, M. A., \& Buck, A. C. (2010). Depression, Anxiety, and Religious Life: A Search for Mediators. Journal of Health and Social Behavior, 51, 343-359. http://dx.doi.org/10.1177/0022146510378237

Strawbridge, W., Shema, S., Cohen, R., \& Kaplan, G. (2001). Religious Attendance Increases Survival by Improving and Maintaining Good Health Behaviors, Mental Health, and Social Relationships. Annals of Behavioral Medicine, $23,68-74$. http://dx.doi.org/10.1207/S15324796ABM2301 10

Warren, J. R., \& Hernandez, E. M. (2007). Did Socioeconomic Inequalities in Morbidity and Mortality Change in the United States over the Course of the Twentieth Century? Journal of Health and Social Behavior, 48, 335-351. http://dx.doi.org/10.1177/002214650704800401

Witter, R. A., Stock, W. A., Okun, M. A., \& Haring, M. J. (1985). Religion and Subjective Well-Being in Adulthood: A Quantitative Synthesis. Review of Religious Research, 26, 332-342. http://dx.doi.org/10.2307/3511048

Yang, Y. (2007). Is Old Age Depressing? Growth Trajectories and Cohort Variations in Late-Life Depression. Journal of Health and Social Behavior, 48, 16-32. http://dx.doi.org/10.1177/002214650704800102

Yang, Y. (2008). Social Inequalities in Happiness in the United States, 1972 to 2004: An Age-Period-Cohort Analysis. American Sociological Review, 73, 204-226. http://dx.doi.org/10.1177/000312240807300202

Zimmer, Z., Chayovan, N., Lin, H. S., \& Natividad, J. (2004). How Indicators of Socioeconomic Status Relate to Physical Functioning of Older Adults in Three Asian Societies. Research on Aging, 26, 224-258. http://dx.doi.org/10.1177/0164027503260624 